\title{
PENGARUH BEKERJA DENGAN SHIFT TERHADAP FAKTOR FISIOLOGIS PEKERJA PABRIK TRIPLEK PT. ADMIRA DI DESA BIBIS KECAMATAN SUKOMORO KABUPATEN MAGETAN TAHUN 2015
}

Novyta Anggraeni .S, dan Trimawan Heru Wijono, Handoyo

\begin{abstract}
Shift work affects the occurrence of physiological factors on workers especially night shift workers. Changes in working time from daylight to night resulted in physiological disorders. Workers can not be changed or workers circadian rhythms that are not able to adjust to changes in working time cause physiological disorders. Therefore, research on the effect of shift work on physiological factors plywood factory workers of PT. Admira rural districts Sukomoro Magetan 2015 Magetan district. respondents.

This research is a descriptive study with the stratified random sampling design of 19

Based on the results of the study, $94.74 \%$ of respondents experienced a physiological disorder. Respondents who experienced a physiological disorder with symptoms of fatigue $75.93 \%$. Male respondents who experience fatigue disorder $47.21 \%, 47.21 \%$ of sleep disorders, and gastrointestinal disorders $55.56 \%$. Female respondents who experience fatigue disorder $38.89 \%$, $27.78 \%$ of sleep disorders, and gastrointestinal disorders $27.78 \%$. This indicates that respondents who experienced a physiological disorder that respondents can not be changed circadian rhythm, or the respondents were not able to adjust to the time change from daylight to night work.

For that we need additional hour of rest and given special facilities to rest for the night shift workers. It should also be noted the division of working time, rest periods, and the worker's age, especially night shift workers to minimize the physiological effects of workers.
\end{abstract}

Keywords: Shift Work, Physiological Effects Disorders

\section{PENDAHULUAN}

Menurut Nurmianto (2004), shift kerja biasanya diterapkan untuk lebih meman-faatkan sumber daya yang ada, meningkatkan produksi, serta memperpanjang durasi pelayanan. Berbeda dengan hari kerja biasa, dimana pada hari kerja biasa pekerjaan dilakukan secara teratur pada waktu yang telah ditentukan sebelumnya. Sedangkan shift kerja dapat dilakukan lebih dari satu kali untuk memenuhi jadwal 24 jam/hari. Shift kerja bnyak diterapkan pada perusahaan yang berjalan secara terus - menerus. Menurut Adnan (2002) bahwa sistem shift kerja menibulkan dampak positif dan dampak negatif. Dampak positifnya seperti memaksimalkan sumber daya yang ada, memberikan lingkungan kerja yang sepi khususnya shift malam, dan memberikan waktu libur yang banyak. Sedangkan dampak negatifnya seperti penurunan kinerja, keselamatan kerja dan masalah kesehatan.

Shift kerja malam berpengaruh terhadap faktor fisiologis, karena tidak semua orang dapat menyesuaikan diri dengan sistem shift, yang membutuhkan banyak sekali penyesuaian waktu, seperti waktu tidur, waktu makan, dan waktu berkumpul bersama keluarga. Menurut Monk (1996) bahwa pada dasarnya semua fungsi tubuh manusia itu berada dalam keadaan siap digunakan pada waktu siang hari. Sedangkan pada waktu malam hari adalah waktu untuk istirahat dan pemulihan sumber energi. Bahwa individu yang tergolong tipe siang mengalami kesulitan dalam menyesuaikan diri dengan kerja shift malam. Individu dengan tipe siang adalah individu yang bangun tidur lebih pagi dan tidur malam lebih awal dari rata - rata populasi.

Shift kerja dan kerja malam hari merupakan kondisi yang dapat menghambat kemampuan adaptasi pekerja baik dari aspek biologis maupun sosial. Shift kerja malam berpengaruh terhadap kesehatan fisik, mental, waktu tidur dan makan, mengurangi kemampuan pekerja, dan meningkatkan kesalahan dan kecelakaan kerja, serta menghambat hubungan sosial dan keluarga. Menurut Tayyari dan Smith (1997) , bahwa perubahan dari bekerja pada siang hari ke bekerja pada malam hari terjadi perubahan ritme biologisnya, dalam hal ini dikenal sebagai Circadian rhythms. Circadian rhythms adalah proses - proses yang saling berhubungan yang dialami tubuh untuk menyesuaikan dengan perubahan waktu selama 24 jam. Circadian rhythms menjadi 
dasar fisiologis dan psikologis pada siklus tidur dan bangun harian. Fungsi dan tahapan fisiologis dan psikologis memiliki suatu circadian rhythms yang tertentu selama 24 jam sehari. Sehingga circadian rhythms seseorang akan terganggu jika terjadi perubahan jadwal kegiatan seperti perubahan shift kerja. Dengan terganggunya circadian rhythms pada tubuh pekerja akan terjadi dampak fisiologis pada pekerja, seperti gangguan gastrointestinal, gangguan pola tidur, dan gangguan kesehatan lain. Circadian rhythms berhubungan dengan suhu tubuh, tingkat metabolisme, detak jantung, tekanan darah, dan komposisi kimia tertentu pada tubuh. Circadian rhythms dipengaruhi oleh faktor lingkungan seperti terang, gelap, dan suhu lingkungan.

Di Indonesia, sistem shift kerja yang banyak digunakan adalah dengan pengaturan jam kerja secara bergilir mengikuti pola 5-5-5 yaitu lima hari shift pagi $(08.00-16.00)$, lima hari shift sore (16.00 - 24.00) dan lima hari shift malam (24.00 - 08.00) diikuti dengan dua hari libur pada setiap akhir shift. Menurut dr. Astrid W Sulistomo, MPH, SpOk, spesialis kesehatan dan keselamatan kerja Universitas Indonesia (2013), bahwa seringnya bekerja lembur menyebabkan insomnia karena terganggunya irama di dalam tubuh yang juga akan berdampak pada gangguan metabolisme tubuh. Idealnya untuk pergantian shift tiap 2 hari, jangan sampai seminggu karena dengan begitu tubuh sudah beradaptasi sehingga akan kaget ketika harus berganti shift.

Dalam penerapannya, ada beberapa industri yang harus beroperasi dalam waktu 24 jam per hari karena proses produksinya yang panjang dan terus - menerus. Pabrik triplek merupakan industri yang menggunakan mesin yang memerlukan penyetelan mesin yang lama dan bergerak di bidang suplai barang. Setiap hari pabrik ini mampu menghasilkan triplek $20 \mathrm{~m}^{3}$, dan dalam sebulan menghasilkan $500 \mathrm{~m}^{3}$ triplek. Pabrik ini beroperasi 24 jam non stop dengan jadwal 6 hari kerja dan setiap hari minggu libur. Shift kerja karyawan di PT. Admira dibagi menjadi 3, yaitu shift pagi, shift sore, dan shift malam. Pergantian shift dilakukan satu minggu sekali dengan perubahan shift dari shift pagi lalu ke shift sore, setelah itu ke shift malam dan memiliki waktu 8 jam kerja. Yang meliputi shift pagi dimulai pukul $07.00-15.00$, shift sore dimulai pukul $15.00-23.00$, dan shift malam dimulai pukul 23.00 - 07.00. Setiap shift kerja memiliki waktu bekerja 7 jam kerja 1 jam istirahat. Dengan jumlah pekerja 246 orang.

Dampak fisiologis yang diakibatkan dari shift kerja seperti kualitas tidur tidak seefektif tidur malam, banyak gangguan dan biasanya diperlukan waktu istirahat untuk menebus kurang tidur selama kerja malam. Menurunnya kapasitas fisik kerja akibat timbulnya perasaan mengantuk dan lelah. Menurunnya nafsu makan dan gangguan pencernaan. Pada survey awal diperoleh data hasil wawancara pekerja shift malam. Dari 10 pekerja terdapat 8 pekerja menyatakan mengalami gangguan tidur, gangguan pencernaan, dan gangguan fisik seperti mudah mengantuk dan lelah. Keluhan tersebut merupakan gejala gangguan fisiologis. Padahal pembagian waktu kerja PT. Admira untuk tiap shift tidak lebih dari 8 jam dan pada akhir minggu setiap shift diberikan libur tidak bekerja, akan tetapi masih terdapat gejala - gejala gangguan fisiologis pekerja. Berdasarkan uraian diatas, maka tujuan penelitian ini adalah untuk menganalisis Pengaruh shift kerja malam kepada faktor fisiologis pekerja Pabrik Triplek PT. Alam Damai Mitra Raya (Admira).

\section{Metode Penelitian}

Jenis penelitian ini adalah penelitian deskriptif yaitu penelitian yang tujuan utamanya meng-gambarkan atau mendeskripsikan keadaan secara objektif dampak fisiologis bekerja shift malam pada pekerja pabrik triplek di PT. Admira. Keadaan yang ingin digambarkan atau dilukiskan, diperoleh dari hasil observasi dan wawancara. Berdasarkan waktunya merupakan penelitian cross sectional, Penelitian ini dilakukan di PT. Admira, Jalan Gajah Mada no.168 Magetan pada bulan Maret Mei 2015. Populasi penelitian ini adalah seluruh pekerja pabrik triplek, dengan jumlah responden sebanyak 19 orang.

Teknik pengambilan sampel dalam penelitian ini adalah stratified random sampling. Observasi dilakukan untuk mengetahui bagaimana keadaan fisik pekerja yang sedang bekerja shift malam yang meliputi pengecilan pupil mata dan kondisi fisik pekerja. Wawancara dilakukan untuk mendapatkan keterangan atau informasi secara lisan dari responden untuk mendukung data hasil observasi. Dokumentasi dilakukan untuk memperoleh data sekender yang dibutuhkan berupa informasi, keterangan dan hal - hal yang membuktikan adanya suatu kegiatan selama bekerja pada shift kerja malam yang dilakukan oleh pekerja. 
hASIL PENELITIAN DAN PEMBAHASAN

1. Dampak fisiologis pekerja dikumpulkan dengan observasi pada masing- masing responden, kemudian dicatat masa kerja yang dikumpulkan dengan pedoman wawancara menggunakan kuisioner.

TABEL 1: DISTRIBUSI DAMPAK FISIOLOGIS PEKERJA BERDASARKAN MASA KERJA PT. ADMIRA TAHUN 2015

\begin{tabular}{cccc}
\hline No & $\begin{array}{c}\text { Masa } \\
\text { Kerja }\end{array}$ & Jumlah & $\begin{array}{c}\text { Persentase } \\
(\mathbf{\%})\end{array}$ \\
\hline 1. & $>1$ tahun & $\begin{array}{c}18 \\
\text { orang }\end{array}$ & 94,74 \\
\hline 2. & $<1$ tahun & 1 orang & 5,26 \\
\hline & Jumlah & $\begin{array}{c}\mathbf{1 9} \\
\text { orang }\end{array}$ & $\mathbf{1 0 0}$ \\
\hline
\end{tabular}

Berdasarkan tabel 1 bahwa yang paling banyak mengalami gangguan fisiologis adalah pekerja dengan masa kerja $>1$ tahun yaitu 18 (94,74\%).

2. Dampak fisiologis pekerja dilihat dari indikator kelelahan dikumpulkan dengan wawancara menggunakan kuisioner.

TABEL 2: DISTRIBUSI DAMPAK FISIOLOGIS KELELAHAN PEKERJA TAHUN 2015

\begin{tabular}{ccc}
\hline Indikator & \multicolumn{2}{c}{ Jumlah } \\
\cline { 2 - 3 } Kelelahan & Ya (\%) & Tidak (\%) \\
\hline $\begin{array}{c}\text { Fokus } \\
\text { Berkurang }\end{array}$ & $\begin{array}{c}13 \\
(72,22 \%)\end{array}$ & $5(27,78 \%)$ \\
\hline $\begin{array}{c}\text { Pupil } \\
\text { Mengecil }\end{array}$ & $\begin{array}{c}16 \\
(88,89 \%)\end{array}$ & $2(11,11 \%)$ \\
\hline Pusing & $\begin{array}{c}12 \\
(66,67 \%)\end{array}$ & $6(33,33 \%)$ \\
\hline
\end{tabular}

Sumber: Data Primer PT. Admira Tahun 2015

Berdasarkan tabel 3 menunjukkan bahwa gejala yang paling banyak dialami pekerja yaitu gejala pupil mengecil 16 orang $(88,89 \%)$.

3. Dampak fisiologis pekerja dilihat berdasarkan gangguan tidur dengan kebiasaan tidur siang dikumpulkan dengan wawancara menggunakan kuisioner.

TABEL 3: DISTRIBUSI DAMPAK FISIOLOGIS PEKERJA BERDASARKAN GANGGUAN TIDUR TAHUN 2015

\begin{tabular}{|c|c|c|}
\hline \multirow[b]{2}{*}{$\begin{array}{l}\text { Indikator } \\
\text { Gangguan } \\
\text { Tidur }\end{array}$} & \multicolumn{2}{|c|}{ Kebiasaan Tidur Siang } \\
\hline & $\begin{array}{c}\text { BisaTidur } \\
\text { Siang } \\
(\%) \\
\end{array}$ & $\begin{array}{c}\text { Tidak Bisa } \\
\text { Tidur Siang } \\
(\%)\end{array}$ \\
\hline $\begin{array}{l}\text { Kantuk } \\
\text { Berlebihan }\end{array}$ & 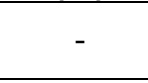 & $\begin{array}{c}12 \\
(63,15 \%) \\
\end{array}$ \\
\hline $\begin{array}{l}\text { Konsentrasi } \\
\text { Menurun }\end{array}$ & $\begin{array}{c}2 \\
(10,52 \%)\end{array}$ & $5(26,31 \%)$ \\
\hline Insomnia & $\begin{array}{c}3 \\
(15,78 \%)\end{array}$ & $\begin{array}{c}11 \\
(57,89 \%)\end{array}$ \\
\hline
\end{tabular}

Sumber: Data Primer PT. Admira Tahun 2015
Berdasarkan tabel 3 menunjukkan bahwa pekerja yang paling banyak mengalami gangguan fisiologis gangguan tidur dengan kebiasaan tidak tidur siang yaitu 12 orang $(63,15 \%)$.

4. Dampak fisiologis pekerja dilihat berdasarkan gangguan pencernaan dengan kebiasaan merokok dikumpulkan dengan wawancara menggunakan kuisioner.

TABEL 4: DISTRIBUSI DAMPAK FISIOLOGIS PEKERJA BERDASARKAN GANGGUAN PENCERNAAN TAHUN 2015

\begin{tabular}{|c|c|c|}
\hline \multirow{2}{*}{$\begin{array}{c}\text { Indikator } \\
\text { Gangguan } \\
\text { Pencernaan }\end{array}$} & \multicolumn{2}{|c|}{$\begin{array}{c}\text { Kebiasaan } \\
\text { Merokok }\end{array}$} \\
\cline { 2 - 3 } & Ya (\%) & $\begin{array}{c}\text { Tidak } \\
(\%)\end{array}$ \\
\hline Tukak & 10 & $\begin{array}{c}1 \\
(5,26 \%)\end{array}$ \\
\hline Sembung & $(52,63 \%)$ & 5 \\
& 2 & $\begin{array}{c}5 \\
(26,31 \%)\end{array}$ \\
\hline Maag & $\begin{array}{c}5 \\
(26,31 \%)\end{array}$ & $\begin{array}{c}4 \\
(21,05 \%)\end{array}$ \\
\hline \multicolumn{3}{|c|}{2015} \\
\hline
\end{tabular}

Berdasarkan tabel 4 menunjukkan bahwa pekerja yang paling banyak mengalami gangguan fisiologis berdasarkan gangguan pencernaan dengan kebiasaan merokok yaitu 10 orang (52,63\%).

Dari 19 pekerja sebanyak 18 orang $(94,74 \%)$ yang bekerja shift malam mengalami dampak fisiologis. Sebanyak 18 pekerja $(94,74 \%)$ yang telah bekerja $>1$ tahun mengalami dampak fisiologis dengan gejala kelelahan, gangguan tidur, dan gangguan pencernaan. Pekerja yang mengalami kelelahan dengan gejala terbanyak yaitu pupil mengecil sebanyak 16 orang $(88,89 \%)$. Yang mengalami gangguan tidur dengan gejala terbanyak kantuk berlebih sebanyak 12 orang $(63,15 \%)$. Dan pekerja yang mengalami gangguan pencernaan dengan gejala terbanyak tukak lambung sebanyak 10 orang $(52,63 \%)$.

Hasil observasi dari dampak fisiologis pekerja menunjukkan gejala gejala seperti gangguan tidur, gangguan pencernaan, dan kelelahan.

\section{KESIMPULAN}

Berdasarkan hasil penelitian dapat disimpulkan bahwa di perusahaan PT Admira Shift kerja memiliki pengaruh terhadap terjadinya gangguan fisiologis pada pekerja. Dalam hal ini pekerja yang tidak dapat berubah ritme sirkadiannya atau pekerja yang tidak mampu menyesuaikan diri 
dengan perubahan waktu kerja dari siang ke malam akan mengalami gangguan fisiologis. Cukup besar angkanya, yaitu 94,74 \%

\section{SARAN}

1. Bagi pekerja agar sebisa mungkin, untuk melakukan gaya hidup sehat mengurangi efek fisiologis akibat shift kerja. Seperti menjaga asupan gizi dan vitamin dengan baik, melakukan tidur siang jika bekerja shift malam, dan berolahraga.

2. Sebaiknya memperhatikan pembagian waktu kerja untuk jangka panjang untuk menghindari gangguan fisiologis pekerja yang bekerja shift malam.

3. Perusahaan menyediakan fasilitas khusus bagi pekerja shift malam seperti ruang tersendiri untuk istirahat.

\section{DAFTAR PUSTAKA}

Agus Harnowo, Putro, 2012. Waktunya Orang Tidur malah Kerja, Akibatnya Kena Insomnia.

Aulia, Uly, 2010. Shift Kerja dan Efeknya.

Job Shifting.

Dirgayudha, Dio, 2014. Faktor-Faktor yang Berpengaruh Terhadap Kelelahan Kerja Pada Pembuat Tahu di Wilayah Kecamatan Ciputat dan Ciputat Timur Tahun 2014.

Ergonomi fit, 2012. Ritme Circadian/Jam Biologis Manusia.

Harimans, Ful, 2013. Proposal Hubungan Pola Tidur dengan Tekanan Darah pada Mahasiswa Dinas Malam di IGD Syekh Yusuf.

Hasanah L, Saftarina F, 2014. Hubungan Shift Kerja dengan Gangguan Pola Tidur pada Perawat Instalasi Rawat Inap di RSUD Abdul Moeloek Bandar Lampung 2013. [online].

Hestya, Inta, 2012. Studi tentang Hubungan Kerja Shift Terhadap Kelelahan Perawat
Di Instalasi Rawat Inap RSUD dr. Sayidiman Magetan Tahun 2012. Karya tulis ilmiah. Program Studi Kesehatan Lingkungan Kampus Magetan. Poltekkes Surabaya. Magetan.

Kusnandar, Khalik, dkk, 2015. Analisis Gangguan Pola Tidur Pekerja Shift Malam dan Dampaknya terhadap Kesehatan serta Perubahan Irama Sirkadian Tubuh.

Lemeshow, Stanley, 1997. Besar Sampel dalam Penelitian Kesehatan. Yogyakarta: Gadjah Mada University Press

Lientje Setyawati Maurits, Imam Djati Widodo, 2008. Faktor Penjadwalan Shift Kerja., Teknoin.Volume 13, Nomor 2,Desember. Halaman $18-22$.

Noval Mauludi, Moch, 2010. Faktor - Faktor yang Berhubungan dengan Kelelahan Pada Pekerja di Proses Produksi Kantong Semen PBD (Paper Bag Division) PT. Indocement Tunggal Prakarsa TBK Citeureup - Bogor Tahun 2010.

Nurmianto, Eko, 2008. Ergonomi Konsep Dasar dan Aplikasinya. Candi Mas Metropole. Jakarta. Guna Widya

Ookinikutau, 2014. Jam Biologis Pada Tubuh Manusia dalam $1 \times 24$ Jam.

Ramadhan, I Putu Arya, 2012. Kesehatan dan Keselamatan Kerja.

Rosanti, Eka, Tarwaka, Seviana Rinawati, 2013. Perbedaan Tingkat Kelelahan Kerja Tenaga Kerja Wanita Antara Shift Pagi, Shift Sore, dan Shift Malam di Bagian Winding PT. Iskandar Indah Printing Textile Surakarta.

Setyawati Maurits, Lientje, Imam Djati Widodo (2008). Faktor dan Penjadwalan Shift Kerja.

Suma'mur, P.K, 1986. Ergonomi Untuk Produktivitas Kerja. Jakarta. CV Haji Mas 